\title{
UV HARDENING AND INTERNAL STRESSES IN WATER BASED LACQUERS
}

\author{
Azemovic E., Horman I., Kostic A. \& PANDZO A.
}

Abstract: Surface treatment of finished products is an important stage in the manufacture of the product itself and requires basic knowledge of both knowledge of liquid materials, surface treatment technology and the method of applying the material to the surface of the workpiece. Today, powder paints are the most common in the production processes of protection of aluminum and other similar materials. As powder films are solid particles, they do not contain harmful organic solvents, and have been shown to be an excellent method when it comes to reducing harmful solvents in paints and varnishes. Prague films show excellent protection against corrosion, wear and mechanical damage. In this paper, the basic properties of powder paints, testing of decorative protective films formed from powder paints are checked. The examination of powder paints included: dry matter content, amount of application, dry film thickness. Examination of the decorative protective film was tested for adhesion.

Key words: film, type and thickness of paint, thickness of substrate
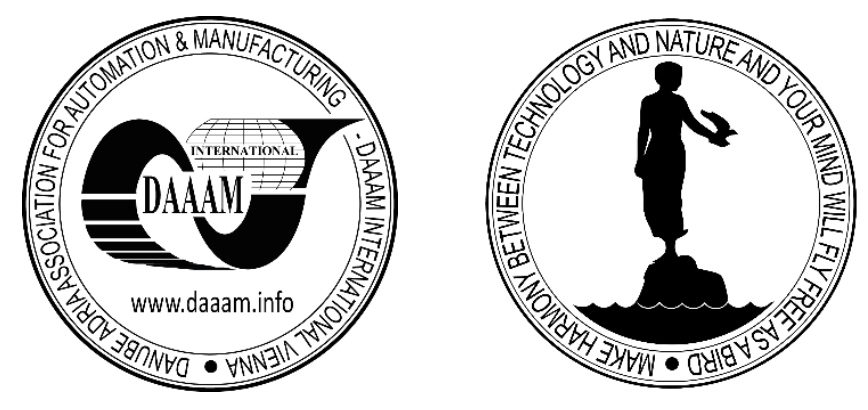

Authors' data: Azemovic, E[sed]; Horman, I[zet]*; Kostic, A[leksandra]*; Pandzo, $\mathrm{A}$ [mina], * Faculty of Mechanical Engineering Vilsonovo setaliste 9, 71000 Sarajevo,BiH, horman@mef.unsa.ba, kostic@mef.unsa.ba

This Publication has to be referred as: Azemovic, E[sed]; Horman, I[zet]; Kostic, A[leksandra] \& Pandzo, A[mina] (2021). UV Hardening and Internal Stresses in Water Based Lacquers, Chapter 13 in DAAAM International Scientific Book 2021, pp.163170, B. Katalinic (Ed.), Published by DAAAM International, ISBN 978-3-902734-310, ISSN 1726-9687, Vienna, Austria

DOI: $10.2507 /$ daaam.scibook.2021.13 
Azemovic, E.; Horman, I.; Kostic, A. \& Pandzo, A.: UV Hardening and Internal Str...

\section{Introduction}

Surface treatment, in a broader sense, includes all types of treatment and treatment of certain surfaces with the aim of improving the quality, appearance and protection of the surface from the effects of various harmful influences. The quality of the finished film formed on the product depends on the application procedures and methods. Modern materials, surface treatments and machines for their application enable industrial production and achieve a cover of highly decorative and protective properties, which ensures dominance in the surface treatment of all final and other products.

Lately, powder coating / film treatments are one of the fastest growing methods of material protection, and therefore many industries are making great efforts in their research and progress. As we find ourselves in a time of growing concern for the environment today, research into new technologies without harmful effects has become a primary goal for many developed countries. Therefore, this interesting topic is often found in the literature (Axelsen, et al., 2008), (Grigore, et al., 2005), (Vela, et al., 2003), (Volinsky, et al.,2002).

The thickness of the substrate and the amount of applied paint in the production processes can cause problems in the quality of the final film. Experimental testing of decorative protective film leads to parameters that affect the quality.

\section{Materials and methods}

In recent years, there have been major changes in the production and application of surface treatment agents. Increasing attention is being paid to technologies and materials systems that pollute the environment less, require less energy and create quality films. In this sense, great research and development efforts are being made, both with the manufacturers of surface treatment materials, and with the manufacturers of technological equipment and, ultimately, the users of these materials.

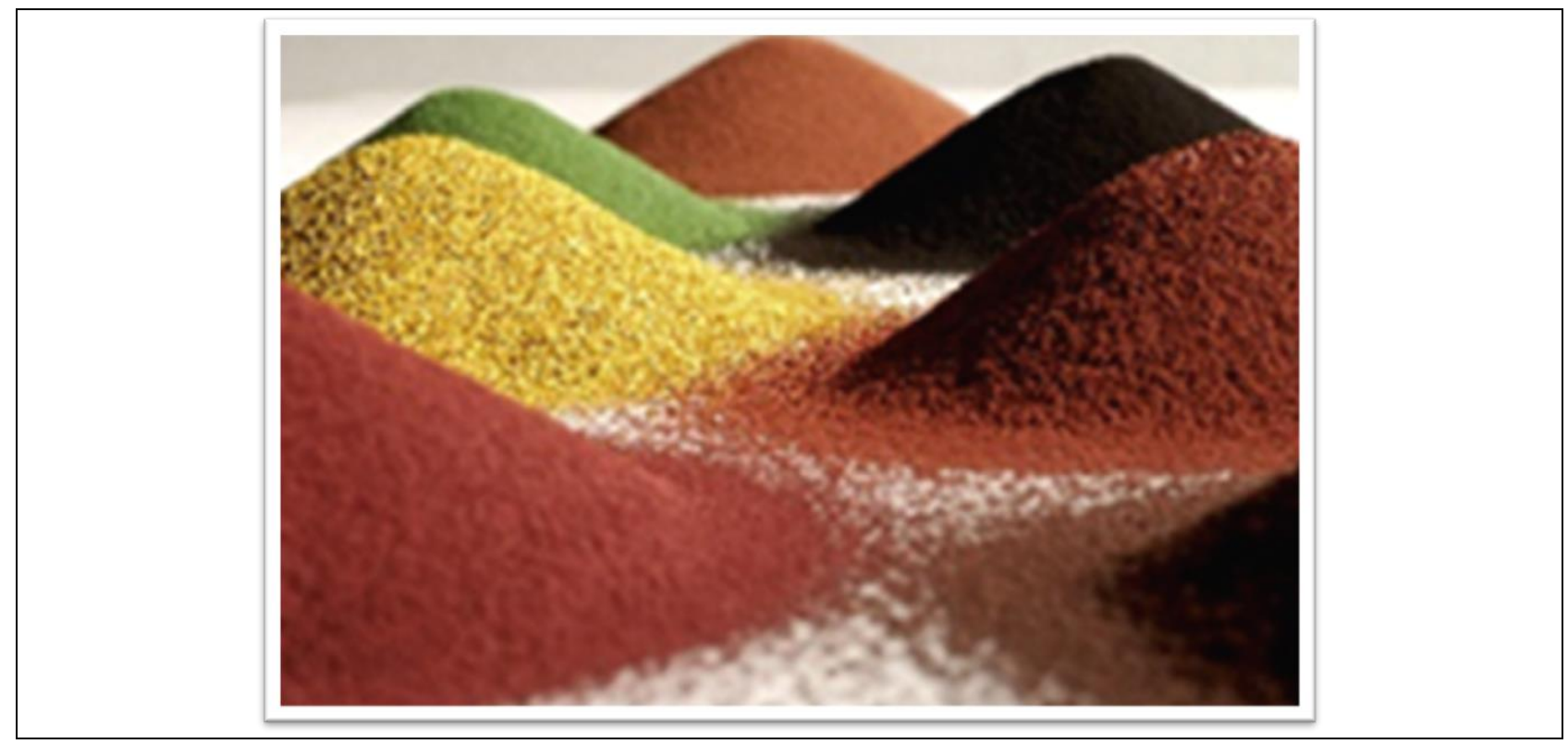

Fig. 1. Powdery paints 


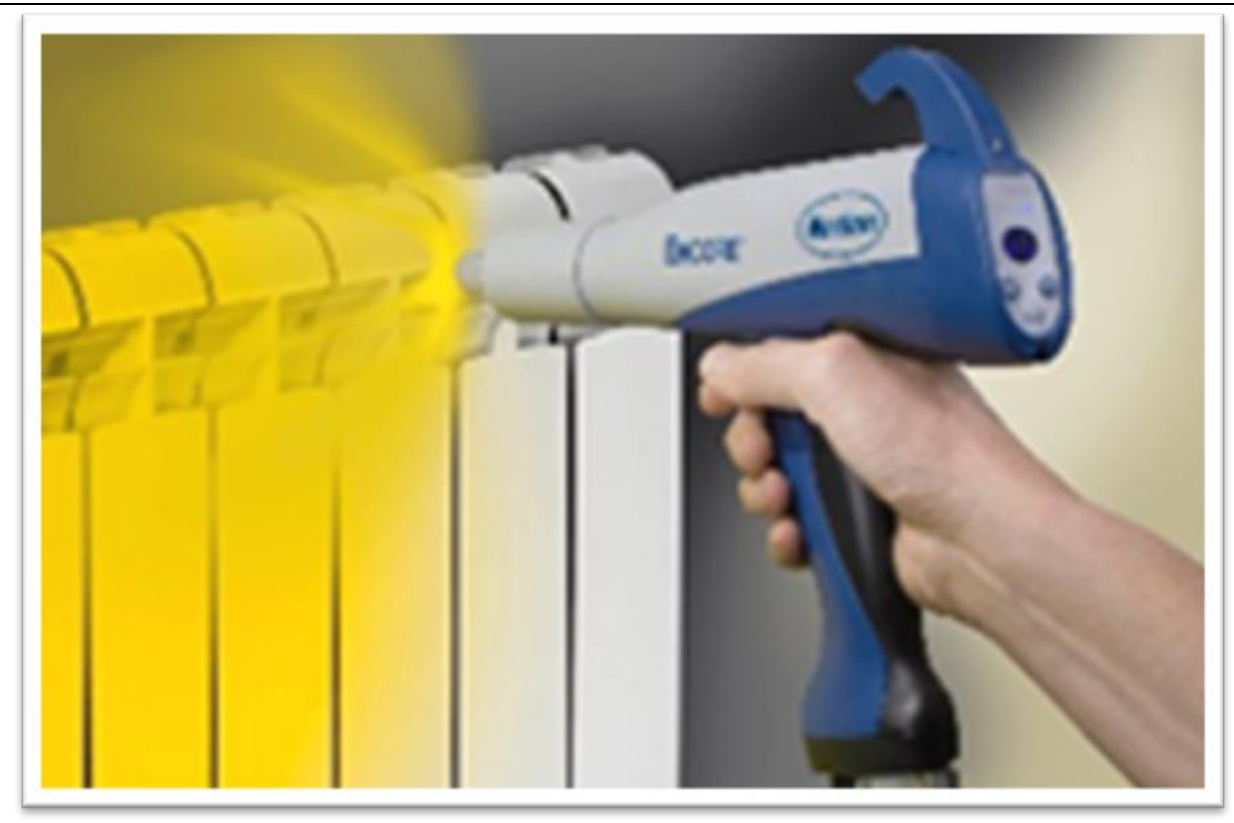

Fig. 2. Electrostatic dusting

Powder paints were used for experimental analysis of the basic properties of decorative protective films. Two types of colors were tested. Structural color [SB] and smooth color [GB]:

\begin{tabular}{|l|l|}
\hline Property & Acrylic resin \\
\hline Basic & {$[\mathrm{SB}][\mathrm{IB}]$} \\
\hline Specific gravity [g / cm3] & 1.04 \\
\hline Dry substance content [\%] & 42.9 \\
\hline Viscosity [mPa.s] & 500 \\
\hline
\end{tabular}

Tab. 1. Structural color [SB] and smooth color [GB]

The powder material is applied to the substrate by electrostatic spraying of particles that form a continuous film on the surface (Axelsen, et al., 2008). The thicknesses applied for the final structural paint are $93 \mu \mathrm{m}$, and for the final smooth paint $81 \mu \mathrm{m}$. The substrate on which the powder paint is applied in this paper is aluminum with dimensions of $250 \times 250 \times 1.5 \mathrm{~mm}$ and $250 \times 250 \times 3 \mathrm{~mm}$.

The main task and goal of the work is to check the basic properties of powder paints, to examine the decorative protective films formed from powder paints.

The main task and goal of the work is to check the basic properties of powder paints, to examine the decorative protective films formed from powder paints in (Smajic, et al., 2020). The examination of powder paints included the dry matter content, the amount of application, the thickness of the dry film. Examination of the decorative protective film was tested for adhesion or adhesion of the film. The test of the decorative protective film was tested for adhesion or adhesion of the film.

Dry matter content (dry matter) means the totality of all substances in the liquid material that remain after the end of the curing-drying process in (Smajic, et al., 2020). In short, these are the substances that form a hard cover or film. 
Azemovic, E.; Horman, I.; Kostic, A. \& Pandzo, A.: UV Hardening and Internal Str...

The content of volatile ingredients means the totality of all evaporated materials which, upon completion of the curing process, do not participate in the formed cover / film. The dry matter content of most liquid materials is determined by forced drying of a certain amount of liquid material. The dry matter content, ie the content of volatile ingredients is calculated according to the forms:

$$
S_{m}=\frac{m_{1}}{m_{2}} 100[\%] \quad S_{i}=100-S_{m}
$$

Where:- $S_{m}$ dry matter content in [\%], Si-content of volatile materials in [\%], $m_{1}$ mass of dried material in [g], $-m_{2}$ mass of weighed liquid material in [g]. Based on the described method, dry matter content was measured for aqueous varnishes applied to the test surface.

Manufacturers of surface treatment materials rarely or never recommend wet film thicknesses for their materials, while it is common to recommend application rates $[\mathrm{g} / \mathrm{m} 2]$. When applying by the method of pouring and dispersing, the amount of application is checked by passing a glass or metal plate of a certain surface through a spout and a spray gun, and by weighing this plate before and after application and from the difference of masses, the amount of application is calculated according to the form:

$$
\theta=\frac{m_{2}-m_{1}}{A}\left[\frac{g}{m^{2}}\right]
$$

$\theta$-amount of application in, $\mathrm{m}_{2}$ - mass of coating plate $[\mathrm{g}]$, $\mathrm{m}_{1}$ - mass of the plate itself $[\mathrm{g}]$, A- surface of the plate in $\left[\mathrm{m}_{2}\right]$.

This procedure regulates the set application rates by adjusting the feed rate of the spout, the feed rate of the gun, and the selection of the appropriate nozzle opening on the gun.

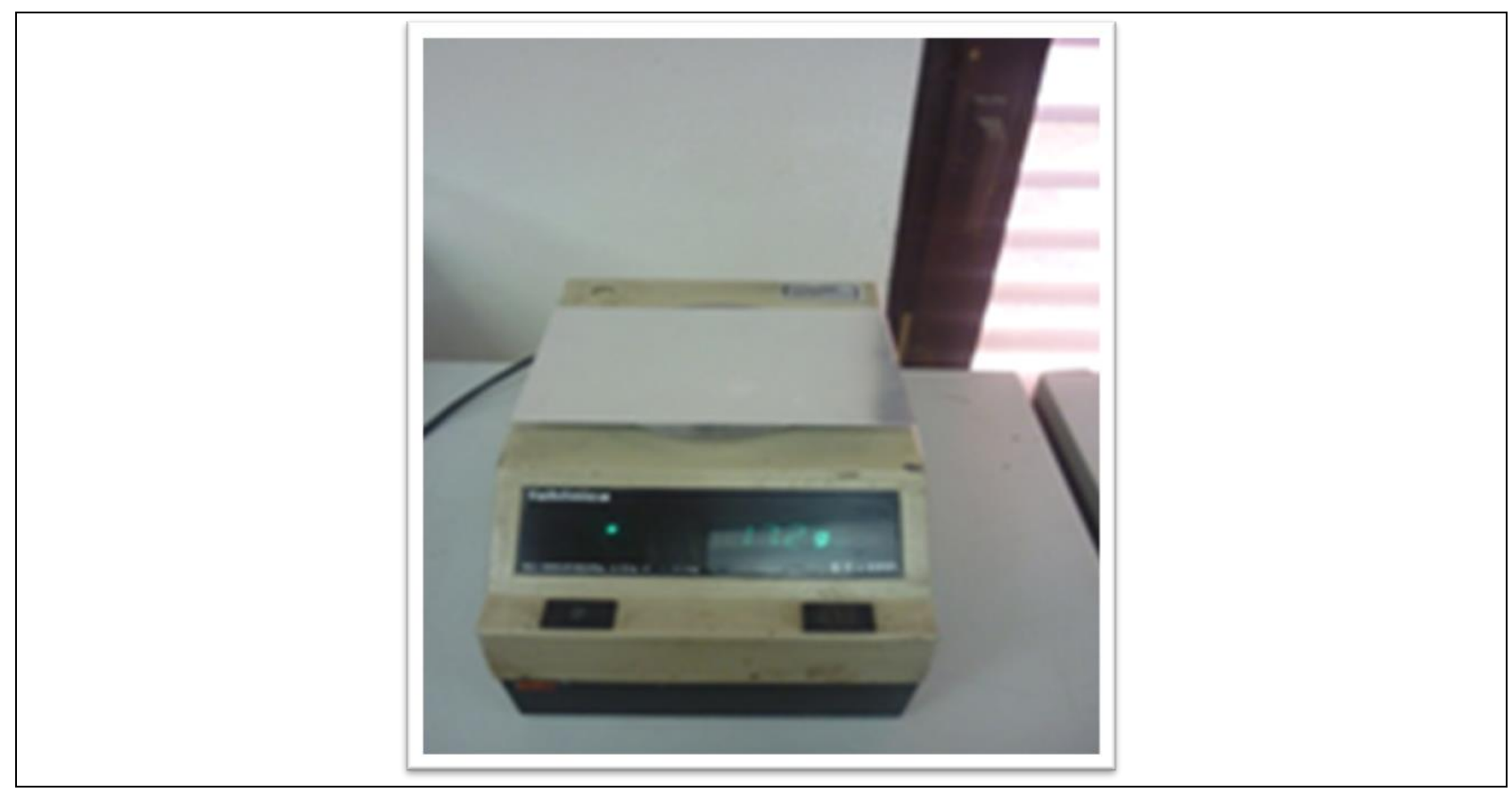

Fig. 3. Hardness test by König-u 


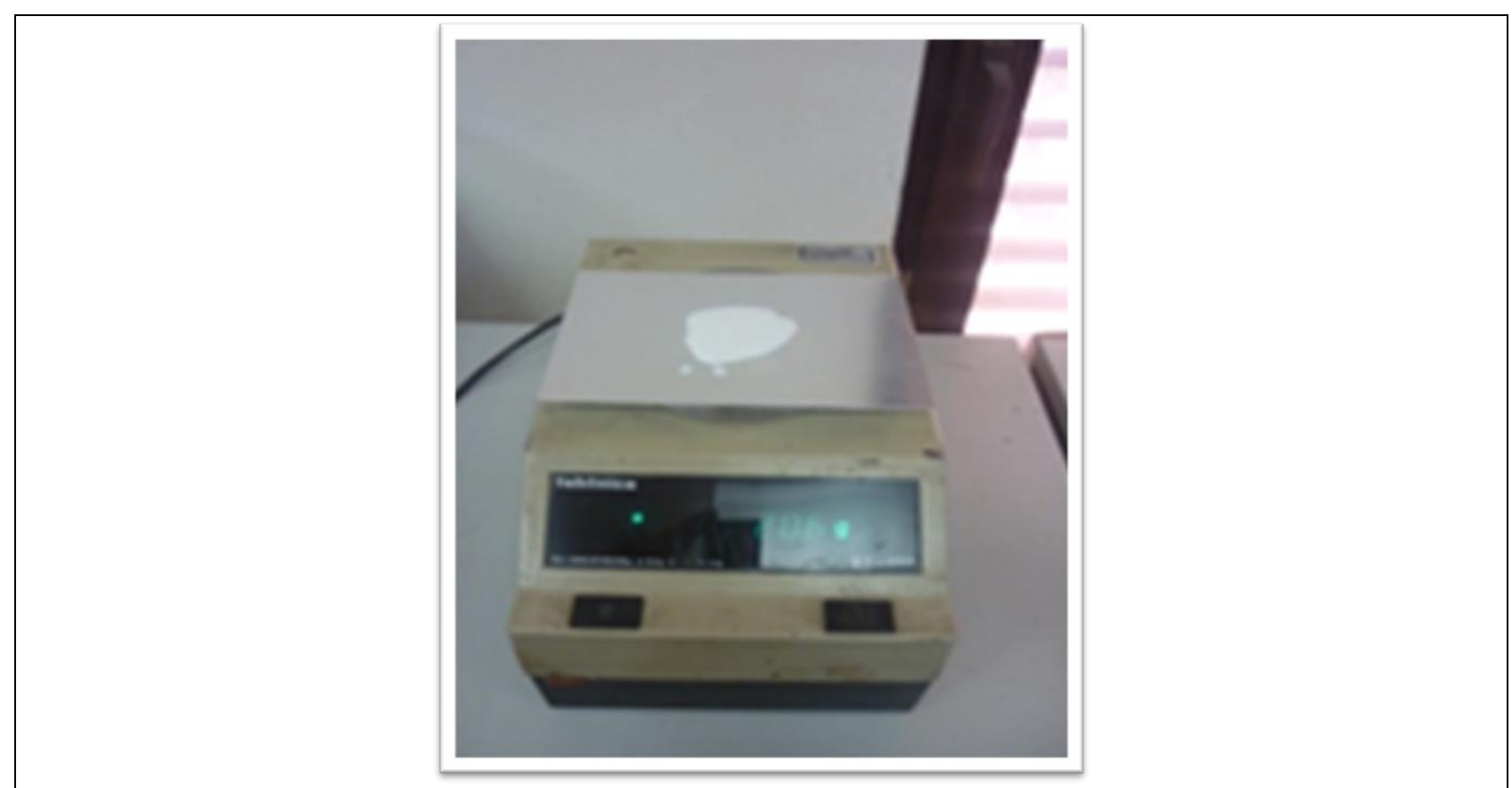

Fig. 4. Hardness test by Clemen-u

Adhesion in surface treatment means the property of forming a strong bond between the film and the substrate. Adhesion is conditioned by the forces of attraction of the film and substrate molecules at the point of their mutual contact and depends on the physicochemical properties of the film and the substrate (Volinsky, et al.,2002). The test was based on lattice cutting of the film. Lattice cutting is accepted by the BS 3900 E6 standard and is performed manually with a set of cutting inserts, Figure 3 . The inserts are fixed at the same distance of $1[\mathrm{~mm}]$. The cutting is done crosswise, so that a grid of cut film with 25 squares is formed.

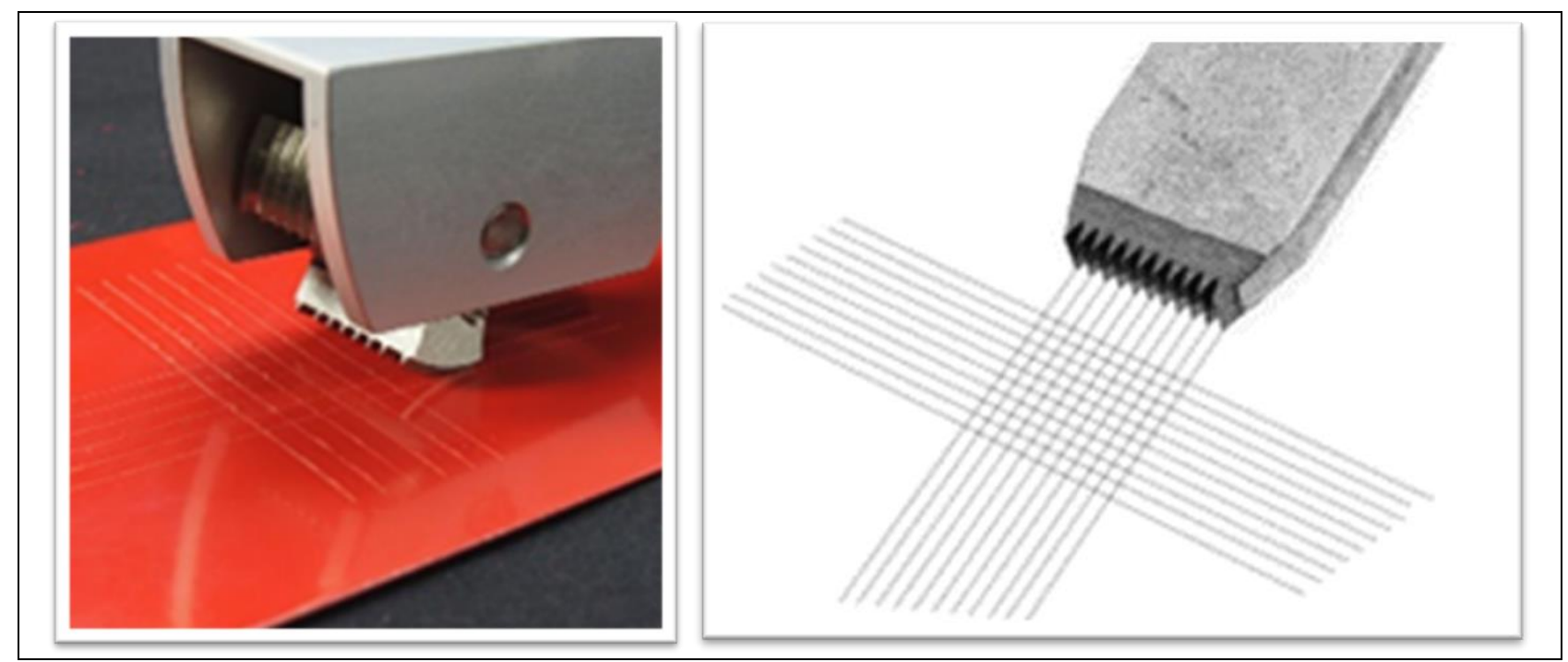

Fig. 5. Lattice film cutting

\section{Results and discussion}

The table 2 shows the results of the dry matter content for powder paints. Powder paints were applied on a substrate 1.5 and $3 \mathrm{~mm}$ thick. A total of 20 samples were tested. 
Azemovic, E.; Horman, I.; Kostic, A. \& Pandzo, A.: UV Hardening and Internal Str...

\begin{tabular}{|l|l|l|}
\hline Test tubes & SB color Sm [\%] & GB color SI [\%] \\
\hline $250 \times 250 \times 1,5 \mathrm{~mm}$ & 94.86 & 94.98 \\
\hline $250 \times 250 \times 3 \mathrm{~mm}$ & 97.16 & 96.98 \\
\hline
\end{tabular}

Tab. 2. Results of dry matter content Sm [\%]

Table 3 shows the results of the amount of powder coats applied to 1.5 and 3 [mm] thick aluminum substrates in (Kapustova. \& Martinkovic, 2012). A total of 20 samples were tested.

\begin{tabular}{|l|l|l|}
\hline Test tubes & SB color Q [g / m2] & GB color Q [g / m2] \\
\hline $250 \times 250 \times 1,5 \mathrm{~mm}$ & 207.7 & 200.5 \\
\hline $250 \times 250 \times 3 \mathrm{~mm}$ & 229.1 & 243.2 \\
\hline
\end{tabular}

Tab. 3. The results of the amount of powder coating $Q$

Physico-mechanical properties of films such as adhesion, hardness, flexibility, internal stresses, resistance to mechanical damage are predominantly dependent on the film thickness in (Kapustova. \& Martinkovic, 2012). When analyzing the internal stresses, it can be noticed that the film thickness has a significant influence on the stress intensity (Graph 1). The table 4. shows the thicknesses of dry films for different amounts of coating and substrate thicknesses.

\begin{tabular}{|l|l|l|}
\hline Test tubes & SB color $[\mu \mathrm{m}]$ & GB color $[\mu \mathrm{m}]$ \\
\hline $250 \times 250 \times 1,5 \mathrm{~mm}$ & 81.4 & 93.4 \\
\hline $250 \times 250 \times 3 \mathrm{~mm}$ & 88.4 & 91.2 \\
\hline
\end{tabular}

Tab. 4. Dry film thickness $[\mu \mathrm{m}]$

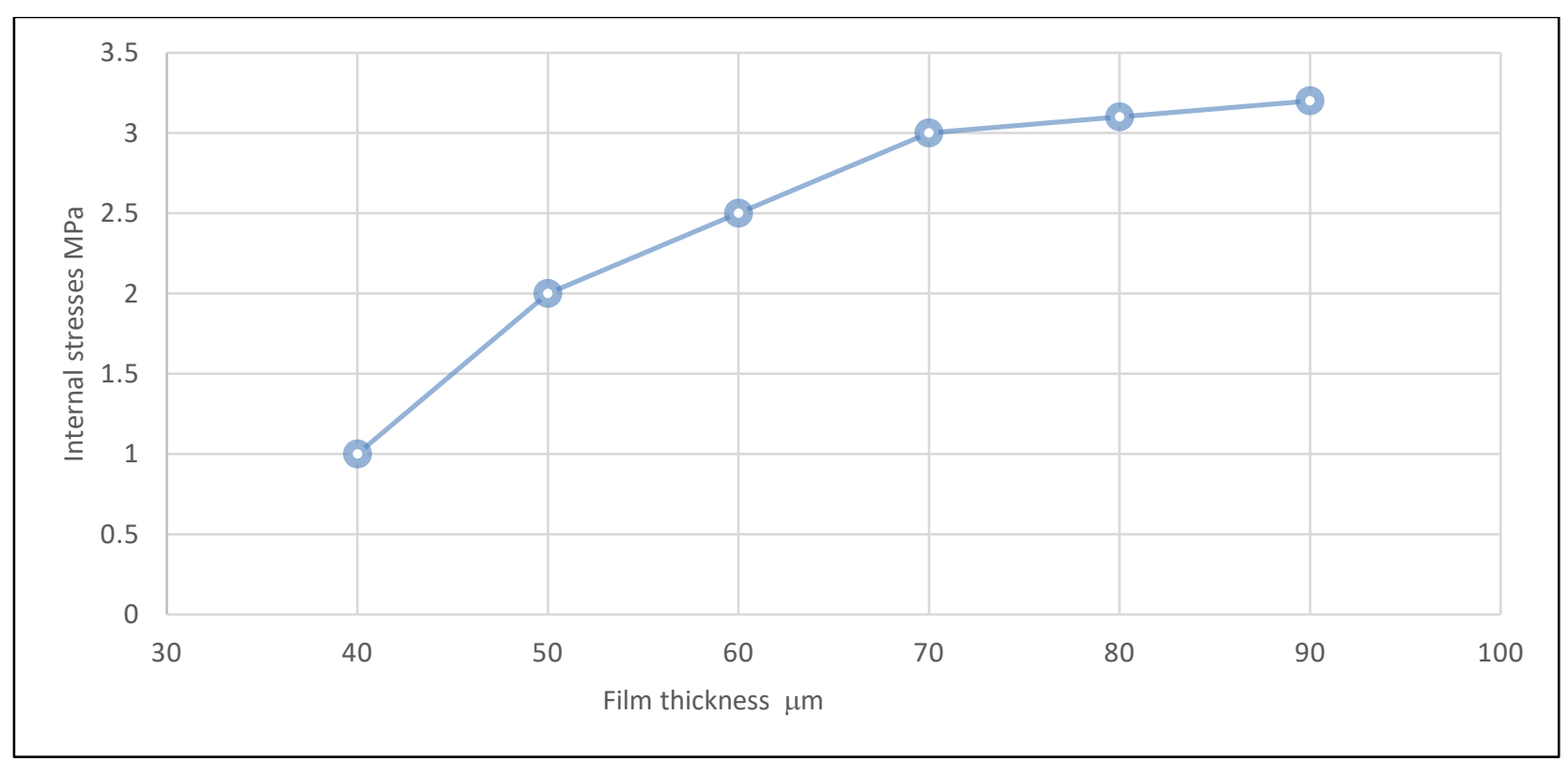

Fig. 6. Internal stresses depending on the film thickness

The adhesion test was performed according to the ISO 2409 standard, which prescribes 6 quality classes in the range from 0 to 5 . 


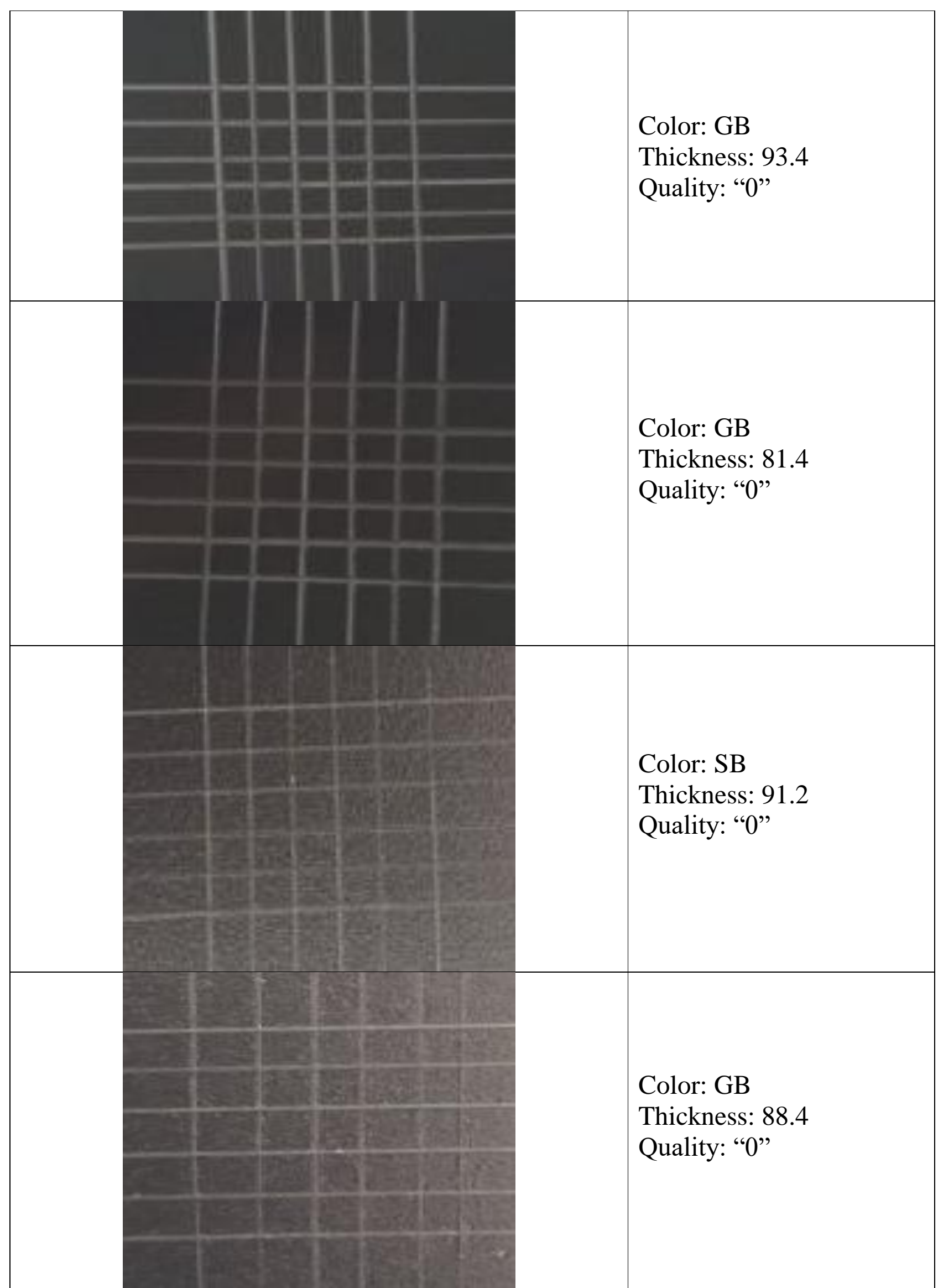

Tab. 5. Sample comparison

The table shows that all samples belong to the quality class "0" (exelent). 


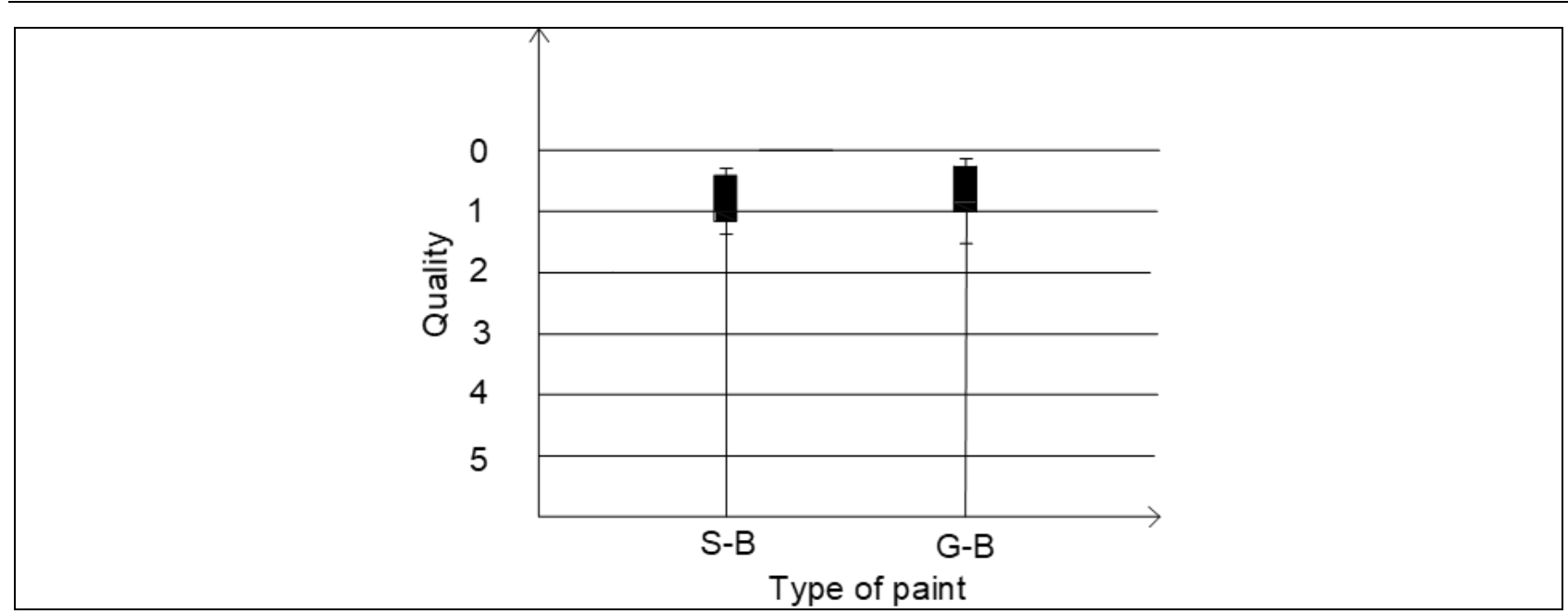

Fig. 7. Adhesion quality of SB and GB for different film thicknesses

\section{Conclusion}

By analyzing the data obtained as part of these tests, we come to the following conclusions:

- The thickness of the substrate has a significant effect on the thickness of the final film.

- The type of powder paint affects the quality of the final film (SB or GB).

- Internal stresses increase with the thickness of the film up to a certain limit.

- Both tested paints show very good results of quality adhesion (exelent), applied in different quantities, or different thicknesses of dry films.

\section{References}

Axelsen, S.T.; et al. (2008). Topcoat flaking - a mechanism study. Party 1; Laboratory testing internal stress, mechanical properties, adhesion and ageing, Corrosion, March16-20, New Orleans, USA, Number of pages 14

Grigore, E.; Ruset, C.; Short,; Hoeft, D.; Dong, H.; Li, X.Y. and Bellt, T. (2005) In situ investigation of the internal stress within the nc-Ti2N/nc-TiN nanocomposite coatings produced by a combined magnetron sputtering and ion implantation method, Surface and Coatings Technology, Vol. 200, Iss. 1-4, Oct 2005, pp. 744-747, ISSN O257-8972 Kapustova, M. \& Martinkovic, M. (2012). Plasticity and Workability of Aluminium Alloy at Warm, published, http://dx.doi.org/10.2507/daaam.scibook.2012.52 Smajic, S.; Jovanovic, J. \& Beljo Lucic, R. (2020). Effect of Different Processing on the Roughness of Oak and Beech Wood, published http://dx.doi.org/10.2507/daaam.scibook.2020.18

Vela, J.B.; Adhihetty, I.S.; Junker, K.; and Volinsky, A.A. (2003) Mechanical Propertis and Fracture Toughness of Organe - silicate Glass (OSG) Low-k Dielectric Thim Films for Microelectronic Application, Int. Journal of Fracture, Vol 119, No.4, pp 487- 499 Volinsky, A.A.; Moody, N.R.; Gerberich, W.W. (2002) Interfacial Toughness Measuremens for Thin Films on Substrates, Act Mater., Vol. 50/30, pp. 441-466 